\title{
Correlations Between Degree of Limb Ischemia in MESS (Mangled Extremity Severity Score) Score in Predicting Amputation or Limb Salvage in Crush Injury at Hasan Sadikin Hospital, Bandung
}

\author{
Deviandri $\mathbf{R}^{1 *}$ and Ismiarto YD \\ Department of Orthopaedics and Traumatology Faculty of Medicine, Universitas Padjadjaran, Indonesia
}

Received: November 01, 2017; Published: November 10, 2017

*Corresponding author: Romy Deviandri, Department of Orthopaedic and TraumatologyFaculty of Medicine Universitas Padjadjaran/Hasan Sadikin General Hospital, Jalan Pasteur No.38 Bandung 40161,Indonesia

\section{Abstract}

Background: Crush injuries to the lower extremities have proven to be a profound challenge to the surgeon. Complex decisions inevitably center about whether to attempt heroic efforts aimed at limb salvage or to proceed with primary amputation. There are many guidance score that can be objectively help surgeons with the decisions. One of them is MESS Score.

Objective: The purpose of this study is to find the correlations between degree of limb ischemia in MESS score component in predicting treatment to Crush lower limb injury patients.

Method: We reviewed the medical record for patients with severe injuries to the lower leg in five years on period of January 2014 to September 2017. The research is a retrospective analytic diagnostic study in 32 patients with 1,7-80,2 range of age (mean=40.95 year old) who suffered from severe lower limb injury. Data was processed based on MESS Score. MESS includes 4 points of observation, which are skeletal\& soft tissue injury, degree of limb ischemia, shock, and age.

Result: The limb ischemic time correlates strongly with the surgeon's decision to treat the crush lower limb injuries. In conclusion, the degree of limb ischemia in MESS score, plays as an important role in determining the treatment on crush lower limb injury patients.

Keywords : Crush Injuries; Limb ischemia; Limb salvage; MESS score; Primary amputation

\section{Introduction}

Crush injury is an injury to the body that characterized by strong pressure on the upper extremities or the lower extremities which cause damage to bones, muscles, arteries, veins, and/or neurological disorders in areas of the body affected. Crush injury most often affected the lower extremities (74\%), followed by the upper extremities (17\%), and the remainder involves the body (9\%). The most frequent causing of crush injury is traffic accidents. Damage to blood vessels in the crush injury cause ischemia and potentially necrotic in the affected area of the body. Necrotic muscle cannot be repaired anymore, with bone and nerve damage from trauma mechanism, and finally the affected limb cannot be used. Necrosis muscle can release myoglobin which if large amounts can cause myoglobinuria. If not treated, myoglobinuria can cause kidney failure. In addition, bleeding from crush injury can result in hypovolemia, which can lead to shock condition and death $[1,2]$.
Treatment crush injury is a challenge for the surgeon. Assessment level of severity injury, and the consideration to do limb amputation or limb salvaged must be done carefully. To assess whether it needs to do limb amputation, Alan Apley created a criteria for amputation, there are $3 \mathrm{D}$ :

i. Dead: If there is damage to blood vessels, which can be ischemia and necrosis at affected extremity, so that condition can lead to be dead limb and cannot be used.

ii. Dangerous: when injuries occur potentially resulting in death, which usually caused by an infection that spreads and result sepsis.

iii. Damned nuisance: When injuries occur quite heavy so the existence of a broken limb would interfere activity of that person. This is usually caused by continuous pain, severe malformations, recurrent sepsis and loss of limb function. 
Criteria established by Apley mainly rely on the subjective assessment of the physician, therefore, Helfet, Howey, Sanders and Johansen makes an objective scoring system to assess crush injury at the affected lower limb, what it can still be saved or to be amputated. The scoring system called the mangled Extremity Severity Score (MESS), which is now widely used around the world. MESS was first introduced to the public in the journal "Limb Salvage Versus Amputation: Preliminary Results of the Mangled Extremity Severity Score", published in 1990. Helfet stated that the scoring system is a predictor and not a absolute procedure. However, because of the accuracy and the ease of application, MESS is a scoring system that is most widely used around the world to assess the viability of the lower extremities after crush injury.*Point multiply by 2 if ischemia Table 1: Mangled Extremity Severity Scoring.
$>6$ hours. If the MESS score 6 or less indicates to limb salvaged, while score is 7 or more indicates to limb amputation.

\section{Method}

We reviewed the medical record for patients with crush injuries of the lower leg in five years on period of January 2014 to September 2017. The research is a retrospective analytic diagnostic study. Data was processed based on MESS Score. MESS includes 4 points of observation, which are skeletal \& soft tissue injury, degree of limb ischemia, shock, and age. Then, we calculate with SPSS. 18 to determine the correlation between MESS Score and the decision, whether limb saving or amputation [3-5].

\begin{tabular}{|c|c|c|}
\hline Type & Explanation & Point \\
\hline \multicolumn{3}{|c|}{ Energy } \\
\hline Low Energy & stab wound, simple closed fracture, small-calliber gun shoot wound & 1 \\
\hline Medium energy & Open fracture, multilevel fracture, dislocation, moderate crush & 2 \\
\hline High energy & Shotgun, high-velocity gun shoot wound & 3 \\
\hline Massive crush & Logging, railroad, oil rig accidents & 4 \\
\hline \multicolumn{3}{|c|}{ Shock } \\
\hline Normotensive & Blood Pressure stable & 0 \\
\hline Transiently Hipotensive & Blood pressure unstable in field but responsive to fluid & 1 \\
\hline Prolonged hypotension & Systolic blood pressure $<90 \mathrm{mmHg}$ in field and responsive to IV fluids in OR & 2 \\
\hline \multicolumn{3}{|c|}{ Ischemia } \\
\hline None & pulsatile, no sign of ischemia & $0^{*}$ \\
\hline Mild & Diminished pulses without signs of ischemia & $1^{*}$ \\
\hline Moderate & No dopplerable pulse, sluggish cap refill, paresthesia, diminished motor activity & $2^{*}$ \\
\hline Advanced & Pulseless, cool, paralyzed, numb without cap refill & $3^{*}$ \\
\hline \multicolumn{3}{|c|}{ Age } \\
\hline$<30$ y.o. & & 0 \\
\hline 30-50 у.о. & & 1 \\
\hline$>50$ y.o. & & 2 \\
\hline
\end{tabular}

\section{Result}

This research have 32 patients with 1,7- 80,2 range of age (mean $=40.95$ year old) who suffered from crush lower limb injuries. The result of the study was shown in the Table 1. From the research, there was moderate correlation between degree of limb ischemia in mess (mangled extremity severity score) score in predicting amputation or limb salvage in severe lower limb injury $(\mathrm{p}=0,00036)$. We can conclude that the degree of limb ischemia in MESS score, plays as an important role in determining the treatment on crush lower limb injury patients.

\section{Discussion}

MESS score system assesses four variables; there are energy which causing trauma, ischemia, shock and age of the patient. Energy which causing trauma is an indicator of severe crush injury or not. With higher energy, we can estimate that the tissue damage that occurs severe enough and need for amputation. With the worsening of pulsation and capillary refill time of extremity, it shows ischemia on the limb, and may already necrosis. Necrotic tissue cannot be used and potentially lead to sepsis that need to be considered for amputation. In patients with worsening blood pressure showed that cardiovascular disease is caused by crush injury. It can be caused by bleeding or sepsis. Therefore, limb amputation is necessary to be done to handle the causes of shock and save the life of patient. The older a person, the ability to repair damaged tissues is getting low, so when they exposed to an severe injury, the ability to recover is lower than before. Therefore, crush injury in the elderly should be considered to be amputated because it is more difficult to maintain the injured limb. By using MESS Score, we can predict the prognosis of the cases, to determine further action, that need limb salvage or limb amputation can be done carefully, with a score of 6 or less indicates that the limb could still be saved, while if a score of 7 or more shows that need for limb amputation.

\section{References}

1. Solomon L, Warwick D, Nayagam S (2010) Apley's System Orthopaedics And Fractures $9^{\text {th }}$ Edition, Hodder Arnold, London. 
2. (2009) US Department of Health and Human Services Centers for Disease Control and Prevention. Crush Injury and Crush Syndrome. American College of Emergency Physician.

3. William S Krost, Joseph J Mistovich, Daniel Limmer (2008) Beyond the Basics: Crush Injuries and Compartment Syndrome.
4. Canale ST, Beaty JH (2013) Campbell's Operative Orthopaedics $12^{\text {th }}$ Edition, Elsevier, Philadelphia.

5. Helfet DL, Howey T, Johansen K (1990) Limb Salvage Versus Amputation: Preliminary Results of the Mangled Extremity Severity Score. Clinical Orthopaedics \& Related Research 256: 80-86.

\begin{tabular}{ll} 
BIOMEDICAL & Assets of Publishing with us \\
RESEARCHES & - Global archiving of articles \\
\hline & - Immediate, unrestricted online access \\
\hline
\end{tabular}

